\title{
Characteristics of the Compensatory Renal Growth of the Remnant Embryonic Chick Kidneys
}

\author{
P. KLUSOŇOVÁ, Z. ZEMANOVÁ \\ Institute of Physiology, Academy of Sciences of the Czech Republic, Prague, Czech Republic
}

Received April 24, 2007

Accepted June 21, 2007

\begin{abstract}
Summary
Growth of the remnant embryonic kidney (the mesonephros), as expressed by wet weight, was more rapid in the chick embryos with experimentally induced unilateral renal agenesis compared to controls. The difference was significant between embryonic days 8-12, when the doubled weights of remnant kidneys were increased compared with the weights of paired control kidneys. The excessive growth of the mesonephros ceased on day 14, when the normal physiological regression of the embryonic kidney begins. In the definitive kidney, the metanephros, no significant differences in weights of the control vs. remnant metanephros were found on days 10-14. The characteristics of increased mesonephric growth were evaluated by determination of DNA/protein ratios in homogenates of the kidneys. Significant cellular hypertrophy was found in both the mesonephros and metanephros of the embryos with URA on day 10. Additionally, a non-significant cellular hyperplasia was also revealed in the remnant mesonephros on day 8 . This gives evidence that the growth stimuli to the mesonephroi were probably strongest between days 8-10 and that they manifested in the remnant mesonephros only.
\end{abstract}

\section{Key words}

Chick embryo $\bullet$ Unilateral renal agenesis $\bullet$ Remnant mesonephros $\bullet$ Compensatory renal growth $\bullet$ DNA/protein ratio

\section{Introduction}

Compensatory growth reactions of the single kidney to a missing counterpart after unilateral nephrectomy or in congenital absence of the contralateral kidney were studied previously in adult experimental animals (Argyris et al. 1969, Terzi et al. 1995, Pfaller et al. 1998). Kidney weight, area of glomeruli, tubular dimensions and DNA, RNA and protein content and their ratio in the remnant kidneys were used for evaluation of compensatory renal growth (Terzi et al. 1995, Sun et al.
2006). These authors found evidence for hyperplastic growth, along with signs of cellular hypertrophy (Wang et al. 1997). Data concerning prenatal response of the remnant kidney are relatively scarce and do not provide an unequivocal picture about the nature of renal growth reactions. For example, absence of proliferative response was found in the rat as well as in the mouse fetuses following fetal nephrectomy (Rollason 1969, Malt and Lemaitre 1969), while cellular hypertrophy was described in fetal lambs (Moore et al. 1979). The reason is likely due to the fact that kidney function is not as crucial for 
the mammalian fetuses, where maternal kidneys provide so much physiological support. We therefore studied the prenatal growth of the remnant kidney in the experimental model of the unilateral renal agenesis (URA) elaborated in the chick embryo (Bishop-Calamé 1966, Wenz et al. 1992, Zemanová and Murphy 2006), which depends exclusively on the excretory function of its embryonic kidneys during all prenatal periods. In addition to assessing embryonic body and renal weights, we also assessed renal (mesonephric and metanephric) DNA and protein contents and their ratio to evaluate more specifically the nature of compensatory renal growth.

Chick embryos were incubated at $37.5 \pm 0.2{ }^{\circ} \mathrm{C}$ in an incubator with forced air circulation. They were killed by a decapitation on days 8-14 and the embryonic kidneys, mesonephroi (MS) and metanephroi (MT), were collected, weighed and frozen in liquid nitrogen. For analysis, kidneys were sonicated in $300 \mu \mathrm{l}$ of $0.15 \mathrm{M}$ $\mathrm{NaCl}$, where $50 \mu \mathrm{l}$ of the homogenate was used for protein content analysis and $250 \mu \mathrm{l}$ was used for DNA determination. Tissue protein content was determined by colorimetry according to (Bradford 1976) using a bovine serum albumin as a standard. DNA was measured by diphenylamine reaction (Burton 1956) using DNA from calf thymus as a standard. Chemicals were purchased from Fluka (Coomassie Brilliant Blue, acetaldehyde), Sigma (bovine serum albumin from calf thymus and DNA), Merck (diphenylamine), and Lachema (acetic acid, sulfuric acid and perchloric acid).

Body weight of the embryos with URA was the same as in controls (Table 1) with the exception of day 14 , when the weight was significantly lower $(\mathrm{p}<0.05)$. Weight of the mesonephros (MSW) - mathematically doubled in embryos with URA to be comparable with controls - was significantly higher on days $8(\mathrm{p}<0.05)$, and $12(\mathrm{p}<0.01)$, on day 10 this difference disappeared and on day 14 the remnant mesonephros was actually smaller, representing only half of the weight of controls.

The weight of the remnant metanephros (MTW) on days 10-14 (again, doubled for an adequate comparison with controls) was never significantly larger in the embryos with URA than in controls.

The ratio of DNA/protein was significantly lower in both remnant MS and MT of embryos with URA on day 10 only. At other ages, no significant differences between remnant and control MS were seen, whereas in the remnant MT we observed a tendency to higher ratio values on days 12 and 14 .
Comparing the DNA/protein ratio in MS and MT - either in remnant kidneys or in controls - it was always lower in the mesonephric kidney.

Our results indicate that the growth of the remaining MS in embryos with URA did occur at a faster rate in the period between days 8 and 12 compared to control embryos (Table 1). The DNA/protein ratio was slightly higher, indicating compensatory renal growth concomitant with the cellular hyperplasia during this period. The hypertrophic growth continued until day 12 , when the doubled remnant MS weight reached values by $50 \%$ higher than MS weight in controls. The $\mathrm{DNA} /$ protein ratio was significantly lower in the remnant MS only on day 10 , demonstrating the compensation of one absent kidney by, at least in part, cellular hypertrophy. A similar physiological response appeared in 10-day remnant metanephros, where the weight of the kidney was also increased due to significant cellular hypertrophy. Beginning with the day 12 the ratio DNA/protein in the remnant MS was comparable to control kidneys and the compensatory growth ceased on day 14. It is evident that the doubled weight of remnant MS was much lower than that of controls on day 14 .

Much smaller changes were observed when the growth of the remnant MT was studied in embryos with URA on days 10-14. It was slightly faster on days 10 and 12 than in controls, but the difference was never significant due to a large scatter of data. The ratio DNA/protein was significantly lower in the remnant MT on day 10. It indicated an important role for cellular hypertrophy and a physiological response for compensatory growth similar to that of the remnant mesonephros. Remnant MT weight, however, never exceeded significantly MT weights of the controls, in spite of the fact that its values were higher on days 10 and 12 (the scatter of the MT weights was also relatively large). The DNA/protein ratio increased almost twice in the remnant MT at these stages, indicating a tendency to a cellular hyperplastic response in the absence of the contralateral MT. However, they did not differ significantly from the control kidneys in our study.

The DNA/protein ratio returned to the control values in the remnant MS beginning at day 12 where it then remained essentially identical to the controls. In the remnant metanephros, the DNA/protein ratio appeared to be higher than in controls on days 12 and 14, but the difference was not significant. However, this may indicate the presence of the cellular hyperplasia, but without significant increase in kidney weight. 
Table 1. Weights and the DNA/protein ratio in the mesonephros and metanephros of embryos with unilateral renal agenesis.

\begin{tabular}{|c|c|c|c|c|c|c|c|c|}
\hline $\begin{array}{l}\text { Age } \\
\text { (d) }\end{array}$ & $\begin{array}{l}\text { BW } \\
\text { (g) }\end{array}$ & $\mathbf{n}_{1}$ & $\begin{array}{l}\text { MS W } \mathbf{W}^{\mathrm{x}} \\
(\mathbf{m g})\end{array}$ & DNA/P & $\mathbf{n}_{2}$ & $\begin{array}{l}\text { MT W' } \\
(\mathbf{m g})\end{array}$ & DNA/P & $\mathbf{n}_{3}$ \\
\hline \multicolumn{9}{|l|}{$\boldsymbol{U} \boldsymbol{R} \boldsymbol{A}$} \\
\hline 8 & $1.05 \pm 0.22$ & 11 & $7.4^{*} \pm 1.5$ & $0.068 \pm 0.029$ & 9 & - & - & - \\
\hline 10 & $2.10 \pm 0.32$ & 9 & $9.4 \pm 2.0$ & $0.026^{* *} \pm 0.003$ & 7 & $6.4 \pm 1.2$ & $0.041^{*} \pm 0.017$ & 7 \\
\hline 12 & $4.27 \pm 0.42$ & 13 & $15.3^{* *} \pm 3.5$ & $0.038 \pm 0.009$ & 10 & $19.5 \pm 5.1$ & $0.084 \pm 0.044$ & 10 \\
\hline 14 & $6.18^{*} \pm 1.12$ & 7 & $7.5 \pm 3.2$ & $0.036 \pm 0.005$ & 5 & $39.3 \pm 11.4$ & $0.074 \pm 0.027$ & 6 \\
\hline \multicolumn{9}{|c|}{ Controls } \\
\hline 8 & $1.05 \pm 0.12$ & 13 & $5.9 \pm 0.5$ & $0.048 \pm 0.01$ & 9 & - & - & - \\
\hline 10 & $2.39 \pm 0.29$ & 11 & $7.9 \pm 1.8$ & $0.032 \pm 0.005$ & 11 & $6.1 \pm 1.7$ & $0.056 \pm 0.011$ & 9 \\
\hline 12 & $4.05 \pm 0.47$ & 13 & $10.5 \pm 3.0$ & $0.038 \pm 0.006$ & 11 & $17.4 \pm 4.7$ & $0.062 \pm 0.030$ & 8 \\
\hline 14 & $7.58^{*} \pm 1.34$ & 13 & $14.2 \pm 5.0$ & $0.032 \pm 0.010$ & 9 & $46.2 \pm 13.1$ & $0.059 \pm 0.012$ & 9 \\
\hline
\end{tabular}

BW - body weight, $d$ - day, DNA/P - ratio DNA/protein, MS W - weight of the mesonephros, MT W - weight of the metanephros, $n$ - number of cases: $n_{1}$ - number of weighed embryos and kidneys, $n_{2}, n_{3}$ - number of measurements of DNA/P in MS and MT, respectively. Significantly different from controls: $* p<0.05, * * p<0.01,{ }^{x}$ ) Weight of the paired kidneys or the doubled weight of the remnant kidney.

On day 14 the growth of the remnant MT was surprisingly reduced below control values. This retardation, however, was present in the body weight and in the MS and MT weights as well. This might be a result of premature MS regression, though it is more likely embryonic growth inhibition due to accumulation of nitrogenous metabolites caused by developing renal failure (Wenz et al. 1992).

It should be noted that the DNA/protein ratio was always significantly lower in MS than in MT, irrespective of being in remnant kidneys or in controls. This is likely due to the difference in cell size because the mesonephric epithelial cells are on average larger than the metanephric cells.

To summarize the findings on the growth of the remnant kidneys in the chick embryos with URA, we observed a clear, compensatory increase in the embryonic kidneys, which were more pronounced in the mesonephros than in the metanephros. We hypothesize that the observed differences between the two types of embryonic kidneys is due to the developmental time gap of five days between their origin and functional differentiation. The MS on day 8 is already fully functional, but the MT only begins to function on day 11 (Junqueira 1952, Mitra 1967). The role of the degree of functional development in the response of the remnant kidneys to the absence of a contralateral kidney is still difficult to characterize. However, in this present study, we further determined that compensatory growth included cellular hyperplasia, which was more pronounced on day 8 in the MS and much less so in the MT on day 10. Cellular hypertrophy was demonstrated exclusively on day 10 . The appearance of these two processes in the hypertrophying remnant kidneys was previously described in adult animals after unilateral nephrectomy (Terzi et al. 1995).

\section{Acknowledgments}

Authors are grateful to Mrs M. Strnadová and Mrs I. Muricová for their expert technical assistance, and to Mrs Alena Dědičová for statistical analyses. This study was supported by the Grant Agency of the Czech Republic No.304/04/0972.

\section{References}

ARGYRIS TS, TRIMBLE ME, JANICKI R: Control of induced kidney growth. In: Compensatory Renal Hypertrophy. WW NOWINSKI, RJ GOSS (eds), Academic Press, New York, 1969, pp 45-58. 
BISHOP-CALAMÉ S: Étude expérimentale de l'organogenese du systeme urogénitale de l'embryon de poulet. Arch Anat Microscop Morphol Exp 55: 217-309, 1966.

BRADFORD MM: A rapid and sensitive method for the quantitation of microgram quantities of protein utilizing the principle of protein-dye binding. Anal Biochem 72: 248-254, 1976.

BURTON K: Study of conditions and mechanisms of the diphenylamine reaction for the colorimetric estimation of desoxyribonucleic acid. Biochem J 62: 315-323, 1956.

JUNQUEIRA LCU: Phosphomonoesterase content and localisation in the meso- and metanephros of the chick embryo. Quart J Microscop Sci 93: 247-257, 1952.

MALT RA, LEMAITRE DA: Nucleic acids in fetal kidney after maternal nephrectomy. Proc Soc Exp Biol Med 130: 539-542, 1969.

MITRA S: Cytochemistry of developing nephric system of the chick embryo. Acta Histochem 26: 46-53, 1967.

MOORE ES, DELEON LB, WEISS LS, MCMANN BJ, OCAMPO M: Compensatory renal hypertrophy in fetal lambs. Pediatr Res 13: 1125-1128, 1979.

PFALLER W, SEPPI T, OHNO A, GIEBISCH G, BECK FX: Quantitative morphology of renal cortical structures during compensatory hypertrophy. Exp Nephrol 6: 308-319, 1998.

ROLLASON HD: Mitotic activity in the fetal rat kidney following maternal and fetal nephrectomy. In: Compensatory Renal Hypertrophy. WW NOWINSKI, RI ROSS (eds), Academic Press, New York, 1969, pp 61-67.

SUN J, LANGER WJ, DEVISH K, LANE PH: Compensatory kidney growth in estrogen receptor-alpha null mice. Am J Physiol 290: F319-F123, 2006.

TERZI F, TICOZZI C, BURTIN M, MOTEL V, BEAUFILS H, LAOUARI D, ASSAEL BM, KLEINKNECHT C: Subtotal but not unilateral nephrectomy induces hyperplasia and protooncogene expression. Am J Physiol 268: F793-F801, 1995.

WANG X, GU F, YANG B: Apoptosis in the early stage of compensatory renal growth following uninephrectomy in the young and old rats. (in Chinese). Zhonghua Yi Xue Za Zhi 77: 742-744, 1997.

WENZ JR, PECK MP, MURPHY MJ: Unilateral renal agenesis in chick embryos: a model for chronic renal insufficiency. Int J Dev Biol 36: 445-450, 1992.

ZEMANOVÁ Z, MURPHY MJ: Compensatory renal hypertrophy in chick embryos with experimentally induced unilateral renal agenesis. In: New Insights into Fundamental Physiology and Perinatal Adaptation of Domestic Fowl. S YAHAV, B TZSCHENTKE (eds), Nottingham University Press, Nottingham, 2006, pp 141-150.

\section{Corresponding author}

Zdeňka Zemanová, Institute of Physiology, Academy of Sciences of the Czech Republic, Vídeňská 1083, 14220 Prague, Czech Republic. E-mail: zemanova@biomed.cas.cz 